\title{
AS CONSULTAS TERAPÊUTICAS E A PSICANÁLISE DE D. W. WINNICOTT*
}

\author{
THERAPEUTIC CONSULTATIONS AND \\ WINNICOTT'S PSYCHOANALYSIS
}

\author{
Gabriel Zaia LESCOVAR ${ }^{* *}$
}

\begin{abstract}
RESUMO
O presente artigo aborda alguns eixos fundamentais da prática de consultas terapêuticas, tais como: a posição metodológica de investigação clínica de Winnicott (envolvendo a construção do conhecimento psicanalítico), o valor intrínseco da experiência na prática clínica, do manejo temporal e do contexto (meio ambiente) favorecedor de experiências constitutivas ao si-mesmo (self) do paciente. Tais aspectos servirão como contextualizadores dessa revolucionária modalidade de trabalho psicológico no interior da clínica winnicottiana, por sua vez, fundamentada segundo o paradigma em psicanálise, guiado pela relação mãe-bebê e pela busca de atualização e constituição do si-mesmo.
\end{abstract}

Palavras-chave: consultas terapêuticas, psicanálise, Winnicott, amadurecimento.

\begin{abstract}
The aim of this paper is to present some of the core elements involved in therapeutic consultations, such as the Winnicott's clinical research methodology perspective (involving the construction of psychoanalytical knowledge), the intrinsic value of experience in clinical practice, and of temporal management and facilitating environment in the constitutive experience of the patient's inner self. Such aspects will provide the context for
\end{abstract}

\footnotetext{
(*) Este artigo foi baseado em dissertação de mestrado, defendida pelo Programa de Pós-Graduação em Psicologia Clínica da Pontifícia Universidade de São Paulo no ano de 2001, sob orientação do Prof. Dr. Zeljko Loparic. Essa mesma dissertação também deve seu favorecimento à CAPES. Para maiores desenvolvimentos e esclarecimentos/ilustrações clínicas: Lescovar, Gabriel Z. (2001) Um estudo sobre as consultas terapêuticas de D. W. Winnicott. Dissertação de mestrado, PUC-SP.

(*) Psicólogo, Psicanalista, mestre em Psicologia Clínica pela PUC/SP, Doutorando pelo IPUSP/SP e Bolsista FAPESP. Endereço para Correspondência: R. Ministro Gastão Mesquita, 769 Apto 24 - Perdizes - São Paulo/SP - CEP 05012-010. E-mail: gabriellescovar@uol.com.br.
} 
a revolutionary way of performing psychological activities within a winnicottian clinic which is grounded on psychoanalytical paradigm; which is, in its turn, based on the mother-baby relationship, and on a search for improvement and self-constitution.

Key-words: therapeutic consultation, psychoanalysis, Winnicott, maturational processes.

\section{AS CONSULTAS TERAPÊUTICAS E A TEORIA DO AMADURECIMENTO HUMANO}

Donald W. Winnicott (1896-1971), renomado psicanalista inglês, responsável pela apresentação de aspectos "tão evidentes, mas tão raramente abordados" (Khan, 1978) da natureza humana no universo psicanalítico, foi, antes de tudo, um homem atento à especificidade de sua prática. Como um "psicanalista agarrado à pediatria", Winnicott constatou a importância das primeiras sessões em psicanálise e psiquiatria infantil. Pressionado pelo grande número de crianças que buscavam seu auxílio, gradualmente configurou o que posteriormente denominou consultas terapêuticas.

Como herdeiro do método psicanalítico freudiano de investigação científica do psiquismo humano, suas constantes reformulações teóricotécnicas só podem ser devidamente compreendidas à luz de sua prática clínica, que lhe impunha novos desafios à psicanálise como, por exemplo, o trabalho de consultas terapêuticas.

No exercício da pediatria, deparou com um grande número de casos de crianças que adoeciam precoce e psicossomaticamente, apesar de diagnosticadas pelos médicos pediatras como fisicamente saudáveis (Winnicott, 1958a). Tal constatação obrigou Winnicott a considerar a dependência do bebê dos cuidados circunstantes ambientais como necessariamente constituintes de seu psiquismo. Na evacuação durante a Segunda Guerra Mundial, como consultor psiquiátrico de crianças encaminhadas a albergues, pôde verificar os efeitos nocivos da privação ambiental que resultavam em tendências anti-sociais e comportamentos delinqüenciais juvenis. Este novo fato veio corroborar suas hipóteses anteriores sobre a influência dos fatores ambientais na saúde psíquica dos indivíduos e também sobre o reconhecimento da obrigatoriedade da inclusão da avaliação ambiental para realização de um diagnóstico completo em saúde mental. Finalmente, conforme descrito em seu artigo de 1954, Winnicott entrou em contato com pacientes esquizóides e esquizofrênicos em estado de regressão à dependência (Winnicott, 1954), quando pôde lançar luz sobre os fatores iniciais da constituição psíquica, inacessíveis pela observação direta das interações entre pais e bebês.

Referências à prática de consultas terapêuticas surgem ao longo de toda a sua obra, mesmo quando não explicitadas nos objetivos ou títulos de seus artigos. A freqüência de menções às consultas terapêuticas sinaliza a mútua influência entre esta prática e a conceituação da clínica psicanalítica winnicottiana.

No prefácio de Consultas terapêuticas em psiquiatria infantil (Winnicott, 1971b), Winnicott localizou explicitamente o início de suas atividades em consultas terapêuticas nos anos vinte:

Minha concepção do lugar especial da consulta terapêutica e da exploração da primeira entrevista (ou primeira entrevista reduplicada) surgiu gradualmente no decorrer do tempo em minhas experiências clínica e privada. Há contudo um ponto que se pode dizer teve significação especial. Em meados dos anos vinte, quando ainda era pediatra praticante vendo muitos pacientes no hospital-escola e dando oportunidade a quantas crianças fosse possível se comunicarem comigo, desenharem figuras e me contarem sonhos, fiquei surpreso com a freqüência com que as crianças sonhavam comigo na noite anterior à consulta. Esse sonho com o 
médico que elas iriam ver obviamente refletia o preparo mental imaginativo delas mesmas em relação a médicos, dentistas e outras pessoas que se supõe sejam auxiliadoras. Também refletiam, em graus variados, a atitude dos pais e a preparação para a visita. Contudo, lá estava eu quando, para minha surpresa, descobri ajustando-me a uma noção preconcebida. (Winnicott, 1971b, p. 12)

Em linhas gerais, as consultas terapêuticas representam uma possibilidade nova e breve de coligir a história de um caso clínico por meio de contato com o paciente, ou seja, obter e conduzir os elementos vitais que possam ajudá-lo na elaboração de um sofrimento ou dificuldade. Buscando esclarecer o trabalho de consultas terapêuticas, Winnicott descreve:

Os princípios aqui enumerados são os mesmos que caracterizam um tratamento psicanalítico. A diferença entre a psicanálise e a psiquiatria infantil [o autor está se referindo às consultas terapêuticas] é principalmente que, na primeira, tenta-se ter a oportunidade de fazer tanto quanto possível [...], enquanto que na última pergunto-me: qual é o mínimo que se precisa fazer? O que se perde fazendo-se tão pouco quanto possível é balanceado por um lucro imenso, uma vez que na psiquiatria infantil tem-se acesso a um vasto número de casos [...] para os quais a psicanálise não constitui uma proposta prática. (Winnicott, 1965a, p. 261)

As consultas terapêuticas, ou a exploração integral das primeiras entrevistas psicológicas, representam uma nova possibilidade de avaliação, intervenção e ajuda psicológica, em que o encontro analítico se respalda basicamente numa comunicação significativa entre os membros do encontro. Tal possibilidade surge exatamente pelo caráter peculiar que marca o momento de pedido de ajuda do paciente, que espera encontrar, na comunicação com o psicoterapeuta, o objeto necessitado para a superação de sua dificuldade e, conseqüentemente, a retomada de seu processo de amadurecimento. A brevidade (variando aproximadamente de uma a três sessões) torna-se possível graças ao elemento norteador do trabalho terapêutico, segundo a clínica winnicottiana, respaldado nas necessidades do si-mesmo (self) e de suas efetivações, que exigem um outro ser humano para cumprir-se.

Como o ser humano se encontra em processo de contínuo amadurecimento - desde o nascimento até a morte-, as consultas surgem como uma possibilidade de intercomunicação e ajuda nas mais diferentes etapas da vida.

No entanto, apesar de as consultas terapêuticas serem consideradas uma nova modalidade de prática psicológica, não podem ser definidas a partir de procedimentos técnicos estanques. A comunicação significativa, isto é, o ponto-ápice dessa modalidade de intervenção e avaliação psicológicas, gradualmente se configura ao longo do próprio processo de comunicação e contato entre analista e paciente. Para surpresa de ambos, em um dado momento, a comunicação significativa apresenta-se muito claramente, por meio da fala, das brincadeiras ou de desenhos comuns aos participantes. A dupla analítica surpreende-se com a emergência de aspectos essenciais da biografia do paciente, relacionados à problemática que o paciente buscava tratar - $\mathrm{e}$ que sequer tinha consciência dessa abrangência que o motivava a buscar auxílio. Diante desse fato comunicacional, o psicoterapeuta conclui um psicodiagnóstico compreensivo psicanalítico.

Em virtude desse caráter surpreendente e flexível das consultas, estas não podem ser definidas por meio de técnicas rígidas, conforme já destacado, ou mesmo estabelecidas anteriormente ao contato analítico. Assim sendo, cada encontro analítico adquire uma configuração própria, resultado da conjunção das interações e características tanto do analista quanto de seus pacientes.

Ainda no prefácio de Consultas terapêuticas (Winnicott, 1971b), Winnicott salientou insistentemente a flexibilidade das conduções clínicas das consultas a rigores técnicos, obrigando a uma reflexão crítica e paralela acerca de sua 
teoria do amadurecimento humano para efetivamente compreendê-la. Para Winnicott, a aplicação cega de uma técnica (e conseqüentemente, enquadre) é inútil para o paciente, porque inadequada às suas necessidades, estabelecidas a priori e sem qualquer contato com o mesmo e sua realidade. Os princípios norteadores da escuta, prática e flexibilidade clínica que regem a condução de consultas terapêuticas (Winnicott, 1971b) advêm da teoria do amadurecimento pessoal, respaldada essencialmente na comunicação humana e nos vários sentidos de realidades que constituem a existência. Por sua vez, tal teoria psicanalítica somente pôde ser gradualmente construída a partir da própria prática clínica de Winnicott. Esta configura uma das características hermenêuticas ou, como outros comentadores da obra winnicottiana denominam, "paradoxais", que definem a obra desse pediatra psicanalista.

Ao circunscrever essa modalidade de trabalho, Winnicott afirma:

A única companhia que tenho ao exploraro território desconhecido de um novo caso é a teoria que levo comigo e que se tem tornado parte de mim e em relação à qual sequer tenho que pensar de maneira deliberada. Essa é a teoria do desenvolvimento emocional do indivíduo, que inclui, para mim, a história total do relacionamento individual da criança até seu meio ambiente específico. (Winnicott, 1971b, p. 06, grifos meus)

Dito de outra forma, a fundamentação das consultas terapêuticas encontra-se no próprio movimento de busca de auxílio da criança e na constatação de que, durante as primeiras entrevistas, o paciente se encontrava particularmente ávido para informar o terapeuta sobre sua dificuldade. Em termos teóricos, Winnicott fundamentou este trabalho segundo sua releitura dos processos transferenciais.

Winnicott realizou uma releitura da transferência a partir do estudo da primeira infância. De acordo com sua teoria do amadurecimento humano, somente por meio dos processos de apercepção e ilusão é que o bebê passa a construir gradualmente a realidade compartilhada. Tais relacionamentos objetais iniciais são, quando favorecedores do desenvolvimento do bebê, necessariamente subjetivos. Para condução de um bom trabalho terapêutico, essa mesma qualidade subjetiva inicial deverá estar presente na transferência das relações terapêuticas de cuidado.

(...) o bebê tem a capacidade, quando a função de ego auxiliar da mãe está em operação, de se relacionar com objetos subjetivos. Neste aspecto o bebê pode chegar de vez em quando ao princípio de realidade, mas nunca em toda a parte de uma vez só - o bebê mantém áreas de objetos subjetivos juntamente com outras em que há algum relacionamento com objetos percebidos objetivamente, ou, objetos ‘não-eu'. (Winnicott, 1962b, p. 56)

Segundo Winnicott, as experiências de vida de uma criança tornam-se pessoais somente enquanto obrigatoriamente submetidas à sua criatividade originária, ou seja, justamente ali, onde a mãe se coloca a serviço do objeto subjetivo necessitado. O mesmo torna-se válido para as relações e conduções transferenciais.

O início das relações objetais é complexo. Não pode ocorrer se o meio não propiciar a apresentação de um objeto, feito de um modo que seja o bebê quem crie o objeto. O padrão é o seguinte: o bebê desenvolve a expectativa vaga que se origina em uma necessidade não-formulada. A mãe, em se adaptando, apresenta um objeto ou um manejo corporal que satisfaz as necessidades do bebê, de modo que o bebê começa a se sentir confiante em ser capaz de criar objetos e criar o mundo real. A mãe proporciona ao bebê um breve período em que a onipotência é um fato da experiência. Deve-se ressaltar que, ao me referir ao início das relações objetais, não estou me referindo às satisfações e frustrações do id. (Winnicott, 1962b, p. 60)

Em Consultas terapêuticas em psiquiatria infantil (Winnicott, 1971b), Winnicott fundamenta a prática de consultas na relação subjetiva de 
objeto da criança, relação esta capaz de favorecer a emergência do brincar mútuo e da comunicação significativa.

Uma primeira implicação dessa concepção é a necessidade de o analista reconhecer ao longo do(s) encontro(s) qual é a problemática que o paciente anseia tratar, isto é, a partir de que necessidade a criança o coloca em lugar de objeto subjetivo? Qual a necessidade mais premente que o paciente anseia por comunicar?

Dessa forma, Winnicott restringe o uso das consultas terapêuticas não por intermédio de quadros psicopatológicos, mas em relação a dois fatores intimamente imbricados: a capacidade/incapacidade da criança em ter esperança em um encontro humano que venha em seu auxílio, e também em relação ao ambiente imediato da criança que poderá ou não fazer bom uso do progresso alcançado por ela por meio da integração favorecida pela consulta. Haverá provisão ambiental familiar (e/ou escolar e/ou da comunidade) capaz de ir ao encontro das necessidades e comunicações da criança (Winnicott, 1965c) após o desbloqueio em seu desenvolvimento decorrente das consultas?

Há uma categoria de casos em que essa espécie de entrevista psicoterapêutica deve ser evitada. Não diria que com uma criança muito doente não é possível se fazer um trabalho eficaz. Mas diria que, se a criança sai da consulta terapêutica e retorna para uma situação familiar ou social anormal, então não há provisão ambiental alguma da espécie necessária e que eu julgaria admissível. Confio em um 'ambiente expectável médio' para encontrar e utilizar as mudanças que ocorrem no menino ou na menina durante a entrevista, mudanças que indicam uma anulação da dificuldade no processo de desenvolvimento.

De fato, a principal dificuldade na avaliação dos casos para essa espécie de trabalho é a de avaliar o meio ambiente imediato da criança. Onde há um poderoso e contínuo fator externo adverso ou ausência de consistente cuidado pessoal, é preciso evitar essa espécie de procedimento, devendo-se sentir inclinado a explorar o que pode ser feito mediante 'tratamento cuidado' ou ainda instituir uma terapia que possa dar à criança a oportunidade para um relacionamento pessoal do tipo geralmente conhecido como transferência. (Winnicott, 1971b, p. 05)

Para ele, o caráter primordial desses encontros é a adaptação ativa do analista às necessidades e expectativas do paciente, segundo a sua compreensão do que se passava com o paciente (por meio da teoria do amadurecimento pessoal) e, conseqüentemente, se necessária, a comunicação verbal desse entendimento no momento adequado. Os objetivos últimos são favorecer (por meio da experiência de surpreender-se) ao paciente uma integração de seus aspectos dissociados e/ou não vividos e a realização concomitante de seu diagnóstico (e conseqüente compreensão do melhor procedimento a ser adotado).

No entanto, é preciso destacar que existem pré-requisitos para o trabalho do psicoterapeuta, para que a comunicação significativa ocorra na(s) consulta(s). Todo o trabalho anterior do psicoterapeuta é favorecer o processo de ilusão por meio de sua postura de confiabilidade e previsibilidade profissional/pessoal e ambiental. (cf. Dias, 1999)

À medida que o paciente começa a sentir que alguma compreensão do seu sofrimento poderá ser atingida, as consultas terapêuticas passam a constituir uma espécie de jogo e interação em que os participantes estabelecem um diálogo por meio de um brincar mútuo. Conforme destacado anteriormente, isso se deve ao fato de o terapeuta colocar-se à disposição do paciente (em estado de devoção e concentração), ciente da oportunidade particular das primeiras entrevistas em psicanálise; por outro lado, o paciente (em busca de auxílio) é movido pela própria expectativa (relação objetal inicialmente subjetiva), pela aliança terapêutica e tendência à integração.

Conforme exposto, durante a realização de consulta(s) terapêutica(s), qualquer condução clínica poderá ser utilizada, dependendo do caminho possível e escolhido pelo paciente em 
questão (e sua necessidade). Poder-se-ão usar desenhos, jogos, brinquedos, diálogos... ou os jogos de rabisco que Winnicott criou. Ele utilizava esse jogo porque gostava, porque facilitava a tomada de notas sobre os acontecimentos das consultas (que eram registrados pelos desenhos produzidos), e não como uma técnica necessária para a realização de consultas.

O jogo de rabisco é apenas uma maneira de entrar em contato com o paciente pelo uso de lápis e papel. Caracteriza-se pela flexibilidade (diferentemente dos jogos de regras, em que está em questão ganhar ou perder) e consiste no seguinte: 0 analista faz um rabisco a esmo, que pode ser transformado pelo paciente em um desenho. Depois o paciente faz o seu rabisco e o analista o transforma em um outro desenho, construindo paulatinamente um caminho de comunicação... Durante o jogo, o analista deixa o paciente escolher livremente se prefere desenhar sozinho, nomear os rabiscos, em vez de produzir ativamente transformações gráficas, ou parar o jogo e conversar...

O jogo de rabisco não deve ser confundido com as consultas terapêuticas em si mesmas, mas considerado elemento facilitador dessas consultas.

Para Winnicott, o modelo de condução do trabalho analítico repousa sobre sua concepção de mãe suficientemente boa. Nesse sentido, o trabalho psicológico realizado na perspectiva de Winnicott, incluindo as consultas terapêuticas, reserva ao analista um posicionamento semeIhante ao da mãe em estado de devoção no cuidado de seu bebê. Para Winnicott, o analista só pode realizar um bom trabalho se puder favorecer o estabelecimento de um espaço potencial, decorrente da confiabilidade e previsibilidade ambiental fornecida. Um analista que consegue brincar pode identificar-se com seu paciente e, ao mesmo tempo, preservar sua identidade pessoal, além de poder iluminar os acontecimentos por meio dos conhecimentos segundo sua teoria do amadurecimento humano (Winnicott, 1971b, p. 10). Originalmente, Winnicott subverte a ordem e submete a psicoterapia ao brincar e não o seu contrário, conforme freqüentemente compreendido psicanaliticamente.

Desejo afastar a atenção da seqüência: psicanálise, psicoterapia, material da brincadeira, brincar, e propor tudo isso novamente, ao inverso. Em outros termos, é a brincadeira que é universal e que é própria à saúde: o brincar facilita o crescimento e, portanto, a saúde; o brincar conduz aos relacionamentos grupais; o brincar pode ser uma forma de comunicação na psicoterapia; finalmente, a psicanálise foi desenvolvida como forma altamente especializada do brincar, a serviço da comunicação consigo mesmo e com os outros. (Winnicott, 1971a, p. 63)

Para Winnicott, o jogo e o brincar sempre foram os veículos úteis e necessários ao processo de comunicação entre paciente e analista, mesmo antes de tomar contato com as contribuições de M. Klein.

Quando repasso os artigos que assinalam o desenvolvimento de meu próprio pensamento e compreensão, verifico que meu presente interesse pela brincadeira, no relacionamento de confiança que pode desenvolver-se entre o bebê e a mãe, sempre constituiu característica de minha técnica de consulta, tal como [...] meu primeiro livro o demonstra (Winnicott, 1931). Dez anos depois, deveria elaborá-lo em meu artigo The Observation of Infants in a Set Situation (Winnicott, 1941). (Winnicott, 1971a, p. 72)

\section{AS CONSULTAS TERAPÊUTICAS E OS MÉTODOS TERAPÊUTICOS PSICANALÍTICOS DE WINNICOTT}

As consultas terapêuticas encontram-se sustentadas pela exploração do período de "luade-mel" que caracteriza tanto as consultas em si mesmas quanto o início do processo de análise, isto é, no caráter particular da transferência, em que o psicoterapeuta é colocado no lugar de objeto subjetivo por qualquer paciente: adulto, 
adolescente ou criança. Dessa forma, em termos clínicos, o analista não deve interpretar ou decodificar esse sentido de realidade subjetiva, mas conduzi-la, facilitando a emergência do brincar, assim como os fenômenos transicionais que emergem nas consultas, ou os objetos transicionais que se apresentam.

Em linhas gerais, Winnicott (1971b) desenvolveu as consultas terapêuticas a partir da otimização do maior instrumento do psicólogo: as entrevistas clínicas. Com uma nova maneira de conceber a natureza humana, Winnicott descobriu no brincar os elementos constitutivos do ser humano, do espaço propício à ajuda psicológica e dos correspondentes fins terapêuticos. Nas consultas terapêuticas, por intermédio da intimidade da interação, uma área comum entre os participantes se constitui, alicerçando comunicações entre os envolvidos a partir da mutualidade da experiência. Para compreensão da área comum de trabalho nas consultas - o brincar -, Winnicott empregou seus conhecimentos sobre as comunicações mãe-bebê:

Considerando-se o par bebê e seio da mãe (não estou afirmando que o seio seja essencial como veículo de amor materno), o bebê tem ímpetos instintivos e idéias predatórias. A mãe tem um seio e o poder de produzir leite, e a idéia de ser atacada por um bebê faminto lhe é agradável. Esses dois fenômenos não entram em relação um com o outro até que a mãe e a criança vivam uma experiênciajuntos. [...] Vejo o processo como se duas linhas viessem de direções opostas, com a possibilidade de se aproximarem uma da outra. Se elas se sobrepõem, há um momento de ilusão, uma experiência que o bebê pode tomar, ou como alucinação sua, ou como algo que pertence à realidade externa. (Winnicott, 1941, p. 279)
Winnicott, ao incorporar o estudo da primeiríssima infância à constituição do ego e do si-mesmo na criança, ampliou consideravelmente a compreensão dos manejos clínicos em psicanálise. Em consultas terapêuticas, o desenvolvimento primitivo do bebê aponta para um tipo particular de comunicação transferencial, na qual o paciente (para alcançar a integração de aspectos cindidos, não vividos e/ou dissociados do simesmo) precisa estabelecer uma comunicação silenciosa e indiferenciada entre eu e não-eu (mãe-ambiente), na qual o terapeuta passa a ser concebido como objeto subjetivo (mãe-objeto).

Nas consultas terapêuticas, a qualidade da interação estabelecida (transferência e contratransferência) está diretamente vinculada ao clima de confiabilidade e previsibilidade que o terapeuta pode oferecer e que a criança ansiosamente espera encontrar. Em consultas, analista e criança estabelecem uma identificação mútua, homóloga à relação mãe-bebê inicial dos processos primitivos do desenvolvimento. Assim como a mãe em estado de devoção, o analista transita entre a realidade subjetiva e a realidade compartilhada, isto é, entre uma identificação maciça com o paciente e a preservação da lucidez quanto à sua obrigação de favorecer e colocar-se à disposição do amadurecimento da criança, buscando reconhecer suas necessidades e, conseqüentemente, adequar seus cuidados, via compreensão, à luz da teoria do amadurecimento humano.

A partir da expectativa e da qualidade do encontro analítico por meio da comunicação subjetiva e silenciosa com o analista, o paciente poderá baixar as guardas defensivas (falso simesmo patológico), aproveitando um estado de relaxamento e não integração, e estabelecer (em seu próprio ritmo) comunicação a partir de seu simesmo verdadeiro, no espaço potencial construído entre analista e paciente. A espontaneidade pessoal (gesto espontâneo) $)^{1}$ deverá surgir como

\footnotetext{
(1) Note-se que, na clínica psicanalítica, segundo Winnicott, necessariamente há a inclusão e a participação corporal dos membros dos encontros analíticos (mesmo que de forma simbólica, por meio das elaborações imaginativas do próprio funcionamento corporal). Ao referir-se ao gesto espontâneo e ao valor clínico da experiência de mutualidade, Winnicott inclui a sensorialidade nos acontecimentos clínicos (inclusive como veículo de trocas comunicacionais transferenciais-contratransferenciais), tal como no jogo de rabiscos.
} 
expressão autêntica do paciente a partir da não integração, e a consulta passará a ser guiada pela imprevisibilidade da comunicação e pela necessidade pessoal da criança.

Em consultas terapêuticas, o setting analítico necessariamente comporta os aspectos relacionados à mãe-ambiente, em que o analista oferece constância, previsibilidade e confiabilidade tanto pelo ambiente físico quanto pela qualidade do cuidado pessoal (em que aceita ajustar-se às expectativas da criança e, com isso, estabelece comunicações por meio do si-mesmo verdadeiro).

A razão pela qual o início de tudo isso é insidioso é que o paciente só gradativamente começa a ter esperanças de que essas exigências sejam atendidas. [...] nunca se trata de dar satisfações à maneira ordinária de sucumbir a uma sedução. Sempre que se proporcionam certas condições, podese trabalhar, e, se não se as fornece, não se pode, e poder-se-ia igualmente nem tentar. O paciente não está ali para trabalhar conosco, exceto quando fornecemos as condições necessárias. (Winnicott, 1964, p. 78)

O resultado da confiabilidade, em termos de integração no tempo e no espaço (e, conseqüentemente, da existência psicossomática), para o paciente, é a experiência de continuidade de ser, advinda da adaptação viva às necessidades da criança daquilo que Winnicott postulou como holding materno ${ }^{2}$. Sobre a confiabilidade, a transferência se desenvolve por meio de uma relação objetal inicialmente subjetiva, a qual oferece as condições e possibilidades para a aquisição de experiências pessoais (advindas da integração ou, em outras palavras, da acontecência da natureza humana). Uma vez que os processos integrativos necessariamente envolvem algum grau de integração psicossomática, o experienciar pode conduzir ao conhecer, diretamente vinculado à situação vivida (e não dissociado, como patologicamente Winnicott concebeu por meio do splitting-off intelect). O conhecer é favorecido pela interpretação do analista, quando necessária. (Winnicott, 1962a; Khan, 1984, p. 248)

É axiomático que, se um setting profissional correto é fornecido, o paciente, isto é, a criança (ou adulto) que se acha em sofrimento trará a aflição para a entrevista sob uma forma ou outra. A motivação é muito profundamente determinada. Talvez seja desconfiança o que se demonstra, ou uma confiança grande demais, ou a confiança é logo estabelecida e as confidências cedo se seguem. Seja o que for que aconteça [surpreenda], é o acontecer que é importante. (Winnicott, 1965b, p. 246)

$\mathrm{Na}$ medida em que as consultas terapêuticas buscam favorecer estados de regressão à dependência e, como isso, à emergência de aspectos da história primitiva da criança (portanto, pré-verbais), o experienciar (fruto da integração alcançada na personalidade) torna-se a principal intervenção das consultas, estando a fala secundariamente imbricada ou implicada como facilitadora do experienciar - procurando dissipar resistências. A particularidade das consultas terapêuticas reside fundamentalmente na elaboração do material não defendido do paciente, próprio à natureza (e da transferência) das primeiras consultas em psicanálise.

Aquilo que eu estou chamando de entrevista psicoterapêutica faz o mais complexo uso possível desse material relativamente não-'defendido'.

(2) Os estudos das relações mãe-bebê, em termos de manejo clínico e interação (comunicação) entre analista e paciente, trouxeram para o primeiro plano a investigação da transferência e contratransferência para real compreensão da natureza do processo analítico. De acordo com Winnicott, "Apesar de não podermos trabalhar sem a teoria que construímos a partir de nossas discussões, seremos inevitavelmente desmascarados por este trabalho, caso nossa compreensão das necessidades do nosso paciente seja mais uma questão de mente do que de psique-soma." (Winnicott, 1955, p. 488). Portanto, as mútuas interações entre transferência e contratransferência, enquanto comunicações (em nível pré-verbal) entre analista e paciente, estão implícitas na prática clínica da psicanálise winnicottiana. (Winnicott, 1960). A maior dificuldade na comunicação aos colegas psicanalistas daquilo de que é feito em situação analítica se deve ao caráter pré-verbal de certas experiências constitutivas do si-mesmo do paciente, as quais Winnicott designou como sagradas em consultas terapêuticas (1971b). 
Há perigo real nesse trabalho, mas há o perigo de não se fazer absolutamente nada, e os riscos provêm da timidez ou da ignorância do terapeuta, antes que o paciente sinta que foi enganado. (Winnicott, 1965b, p. 245)

Nas consultas terapêuticas, Winnicott considera que as interpretações orais não produzem o principal resultado mutativo (segundo terminologia cara a James Strachey ${ }^{3}$ ), mas auxiliam na descoberta, pela própria criança, "do que se achava lá, nela própria” (Winnicott, 19641968, p. 243) - por meio da relação de mutualidade. Nas consultas terapêuticas, o setting analítico e os manejos clínicos assumem primordialmente a função de devolver a criança à própria criança (1971a: BR). Para Winnicott, esta é a essência da terapia: o favorecimento dos processos de integração da personalidade sustentado pelo holding (inclusive handling e apresentações de objetos) e pela função especular do analista (inclusive dos aspectos psíquicos referentes ao inconsciente reprimido).

Neste momento, cabe destacar que objetivo subjetivo não é o mesmo que objeto transicional; sendo o primeiro necessário à emergência da segunda realidade experienciada. Enquanto Winnicott reserva ao objeto subjetivo o uso dado pelo bebê aos objetos iniciais criados a partir de sua criatividade originária (graças ao apoio egóico materno capaz de promover a dupla dependência), ele reserva aos objetos transicionais o uso posterior dado pela criança à primeira possessão não-eu, decorrente da área de experiência intermediária da vida humana (entre a realidade subjetiva e objetivamente compartilhada).

No trabalho de consultas, o que é solicitado ao analista é manejo clínico, sustentação da experiência da criança ao longo do tempo, do espaço e da realidade construída pela própria necessidade da criança, a cada momento do processo comunicacional. Só por meio dos manejos adequados do analista é que a comunicação significativa se torna possível, uma vez que a brincadeira não foi interrompida pelo interpretar prematuro do analista. Dito de outra forma, o psicoterapeuta não precisa "caçar" significados ou procurar desvelar sentidos; é preciso que ele saiba ouvir o que o paciente tem a comunicar, respeitando o ritmo, as características pessoais do seu paciente e, principalmente, a realidade experiencial em que a dupla se encontra a cada momento da entrevista psicoterapêutica. Para Winnicott, interpretar os objetos subjetivos e/ou transicionais é reduzi-los às representações do mundo interno da criança, ou seja, é violentar o próprio campo experiencial do paciente, minando o caminho mesmo que possibilita qualquer trabalho terapêutico. O que Winnicott realizava nas consultas era fruto do uso dado ao analista e dos vários sentidos de realidades experienciados pela criança no decorrer da própria consulta.

Em virtude das características das consultas terapêuticas, estas possibilitam o aparecimento de necessidades e questões psíquicas do paciente nos diferentes momentos do processo de amadurecimento, dependendo da história de vida e cronologia da criança.

Partindo do mesmo princípio de que nenhum acontecimento em consulta deve ser despregado de seu contexto de surgimento, isto é, de sua realidade experiencial (quer subjetiva, transicional ou simbólica compartilhada), na própria introdução às Consultas terapêuticas em psiquiatria infantil (1971b), Winnicott contrasta a sua maneira particular de fazer uso dos desenhos das crianças em consultas com a maneira tradicional de compreendê-los psicanaliticamente, isto é, freqüentemente reduzidos aos seus conteúdos representacionais.

\footnotetext{
(3) Ao se referir à clínica de Winnicott em comparação com o destaque dado por Strachey aos insights interpretativos na transferência, diz Khan (1984): "A interpretação mutativa, para usar a expressão de James Strachey (1934), é facilitada, alimentada e possibilitada por muitos outros fatores além da linguagem falada e compreendida na situação analítica e da relação total entre o paciente e o analista. [...] O argumento básico deste trabalho é que as realidades experienciais humanas empregam e se comunicam por outros meios além da linguagem [como a comunicação silenciosa, subjetiva, transicional...], e trocam importantes dados através de aparelhos de ego que não a fala. As consultas com crianças, em que Winnicott (1971b) emprega o jogo de rabiscos (...), não deixam dúvidas a respeito." (Khan 1984, p. 301)
} 
Alguém pode possuir uma leve tendência doutrinária a pensar que todas as cobras são símbolos fálicos, e é claro que podem ser. Contudo, se se pegar o material primitivo e as raízes do que um pênis pode significar para uma criança, ver-se-á que o desenho feito por ela de uma cobra pode ser a configuração do eu (si-mesmo) que ainda não usa braços, dedos, pernas e artelhos. Pode-se ver quantas vezes pacientes não conseguem exprimir um senso de eu (si-mesmo) porque o terapeuta interpretou uma cobra como um símbolo fálico. (Winnicott, 1971b, p. 18)

Winnicott jamais compreendia qualquer produção da criança deslocada de seu contexto de produção, ou momento característico da consulta. O desenho isoladamente destacado pode ser mal compreendido se não for tomado no interior do caminho de comunicação que se estabelece na consulta. Tal como insinuado anteriormente, este é um eixo fundamental do modelo investigativo de Winnicott - jamais compreender qualquer acontecimento clínico despregado de seu contexto originário. Jamais compreender o homem desprovido de seu meio ambiente.

Coerentemente com toda a clínica psicanalítica winnicottiana, as consultas terapêuticas são modalidades específicas de intervenção e ajuda que se fundamentam no favorecimento de situações (um tempo, um espaço e uma relação analítica) facilitadoras dos processos integrativos e constituintes do si-mesmo do paciente. Assim sendo, tal aspecto das consultas aglutina a concepção de Winnicott, a qual define a indissociabilidade entre a compreensão do ser humano e as condições ambientais que permitem que a natureza humana aconteça. Winnicott freqüentemente afirmava: "Não existe essa coisa chamada o bebê" - como forma de salientar o contexto, o qual favorece que a criança continue existindo.
Com relação ao conhecimento psicanalítico, as consultas terapêuticas não podem ser definidas como psicanálise, no sentido tradicional do termo, nem mesmo como psicoterapia breve psicanalítica, exatamente pela brevidade de sua intervenção (uma a três sessões) e principalmente (tal como destacado anteriormente) por responderem a uma necessidade específica do paciente, não sendo realizado um tratamento exaustivo ou focal da transferência. Em outras palavras, o que realmente define as consultas são a utilização e a condução da transferência relacionada ao lugar subjetivo atribuído ao psicoterapeuta pela criança (preestabelecida antes da consulta) ${ }^{4}$, de forma que a transferência seja utilizada no favorecimento ao paciente de uma experiência constitutiva completa (Winnicott, 1941). Desse modo, não se busca uma "resolução" ou uma "resposta conclusiva" à problemática do paciente, mas a integração, na presença de outrem significativo, de alguma dificuldade, sofrimento ou qualquer aspecto dissociado da personalidade.

Winnicott postula que a existência humana parte da não integração primária e da dependência absoluta, sendo o processo de amadurecimento humano fruto da tendência ao crescimento e à integração dos vários aspectos da personalidade, que deverá adquirir o estatuto de unidade psicossomática no tempo e espaço. Para isso, a tendência à integração (que não é uma determinação) ou as tendências hereditárias precisam encontrar uma ambiência favorável para concretizar-se. Tal ambiência é promovida, inicialmente, pelo cuidado humano e pessoal materno (assim como toda a família e sociedade - em um contexto mais amplo) para com as necessidades de seu filho, que, à medida que se desenvolve, adquire um eu individualizado.

Quais as condições ambientais destacadas por Winnicott e necessárias ao acontecer do processo de amadurecimento humano? Quais as condições proporcionadas pela família a fim

\footnotetext{
(4) A criança vem à(s) consulta(s) almejando encontrar o objeto necessitado para retomada de seu processo de amadurecimento humano e superação de sua dificuldade, tal como belamente descrito e apresentado por meio de suas consultas terapêuticas em Consultas terapêuticas em psiquiatria infantil (Winnicott, 1971b).
} 
de que o si-mesmo da criança venha a se atualizar e se constituir? A partir das considerações psicológicas sobre a importância constitutiva do meio ambiente, quais as condições ambientais necessárias ao terapeuta para promoção e realização das consultas?

Por intermédio de suas práticas clínicas como pediatra e psicanalista de pacientes até então "intratáveis" pela psicanálise (crianças com meses de idade, pacientes psicóticos e bordelines, pacientes com traços anti-sociais), Winnicott renomeou e conceitualizou os detalhes e as sutilezas do cuidado materno - holding, handling, apresentação de objeto e função especular. Estes aspectos são decorrentes das noções, do próprio autor, de preocupação materna ou apoio egóico às experiências do bebê.

Por holding, Winnicott compreendia o favorecimento ambiental à integração pessoal do bebê no tempo e espaço advinda do segurar físico e emocional realizado pelo meio ambiente, resultando em experiências fornecidas à criança que estão relacionadas com a estabilidade do meio ambiente, constância objetal e autenticidade dos cuidados maternos. Para Winnicott, o essencial residia na maneira de ser da mãe, em seu estado de devoção/identificação com seu filho, que, por sua vez, Ihe conferia uma certa qualidade no cuidar de seu bebê. Para esse exímio observador, o ser humano jamais poderia ser tratado como um ser natural reduzido a cuidados puramente técnicos. Por meio do holding fornecido à criança, Winnicott postulou que esta, gradualmente, viria a adquirir um senso de identidade pessoal.

Quanto ao handling, Winnicott entendia o favorecimento do meio ambiente ao alojamento da psique no corpo facilitado pelas experiências mãe-bebê, em que a interação entre eles era mediada pelo contato corporal, e também pelas compreensões maternas das manifestações corporais do bebê como comunicações pessoais. Por meio do handling, Winnicott conceituou o estabelecimento da personalização.

Por sua vez, a apresentação de objetos, Winnicott a compreendia como o benefício resultante das relações objetais iniciais entre mãe-bebê em que mãe em estado de devoção fornecia o objeto necessitado pela criança, no momento mesmo de sua necessidade, conferindo ao gesto materno a qualidade de precisão. Tal cuidado era guiado não por uma técnica artificialmente compreendida e aplicada, mas pelo reconhecimento materno das necessidades do bebê em um período de vida pré-verbal deste. Por intermédio da apresentação de objetos, Winnicott postulou o estabelecimento gradual da realidade compartilhada e o senso de realização pessoal.

À medida em que o ambiente facilitador, ou expectável médio, se modifica e se ajusta às necessidades dinâmicas emocionais da criança em crescimento e desenvolvimento por meio da reciprocidade, da mutualidade e dos cuidados adaptados, este passa a constituir o que Winnicott denominou de função especular, que nada mais é que o favorecimento de experiências à criança, de tal forma que esta possa reencontrar-se por meio dessas experiências, tornando-as gradativamente como pessoais. Pode-se denominar a função especular como a integração gradual pessoal do bebê por meio do olhar materno/ambiental que reconhece a sua singularidade pessoal.

Se, por intermédio da teoria do amadurecimento pessoal, Winnicott conceituou as condições necessárias ao processo de amadurecimento pessoal; em termos clínicos significou a promoção de situações facilitadoras da constituição do si-mesmo do paciente, seja na análise padrão (Winnicott, 1986a), nas consultas terapêuticas (Winnicott, 1971b), ou mesmo de acordo com o "trabalho segundo a demanda", descrito em Piggle: relato do atendimento psicanalítico de uma menina (Winnicott, 1977).

$\mathrm{Na}$ clínica winnicottiana o essencial da condução clínica encontra-se no favorecimento de experiências constitutivas ao paciente. A clínica winnicottiana é uma clínica da 
acontecência $^{5}$, uma vez que o si-mesmo se constitui a partir de experiências e do brincar.

Em Consultas terapêuticas em psiquiatria infantil (1971b), Winnicott afirma:

Deve-se observar que neste trabalho eu geralmente não faço interpretações, mas espero até que o traço essencial da comunicação da criança seja revelado. Assim, falo sobre o traço essencial, mas o mais importante não é tanto eu falar quanto o fato de a criança ter encontrado alguma coisa. (Winnicott, 1971b, p. 79)

Para Winnicott, interpretar é tão importante quanto não interpretar; isso porque as interpretações devem estar submetidas à criatividade originária do paciente e ao brincar. A interpretação fora da área comum construída a partir do espaço potencial é doutrinação ou produz traumas ao paciente, obrigando-o a submeter-se ou a reagir à invasão.

Os pacientes que manifestam capacidade limitada de identificação introjetiva e projetiva apresentam sérias dificuldades para o psicoterapeuta, que necessita sujeitar-se ao que é chamado de atuação (acting out) e de fenômenos transferenciais que dispõem de apoio instintual. Em casos assim, a principal esperança do terapeuta é ampliar o campo de ação do paciente com respeito a identificações cruzadas, e isso surge não tanto pelo trabalho de interpretação quanto através de certas experiências específicas que ocorrem nas sessões analíticas. Para chegar a essas experiências, o terapeuta tem de levar em consideração um fator temporal e não se podem esperar resultados terapêuticos de tipo instantâneo. As interpretações, por precisas e oportunas que sejam, não podem conceber a resposta completa.

Nessa parte específica do trabalho do terapeuta, as interpretações têm mais a natureza de uma verbalização de experiências no presente imediato da experiência da consulta; e o conceito de interpretação como verbalização do consciente nascente não se aplica exatamente aqui. (Winnicott, 1971a, p. 163/4)

Em outras palavras, o que Winnicott reafirma é que a "psicanálise é uma forma altamente especializada do brincar" em que a própria interpretação deve ser submetida à capacidade do paciente de jogar, a partir de sua criatividade originária.

Conforme exposto, outro aspecto importante da psicanálise winnicottiana, e essencial para compreensão dos procedimentos clínicos e fins terapêuticos das consultas terapêuticas, encontra-se na concepção particular winnicottiana que envolve a saúde psíquica dos indivíduos. Winnicott passa a deduzir o grau de sanidade de alguém não pelo seu quadro psicopatológico, mas pela presença ou ausência do sentimento de esperança na busca pelo encontro com o objeto necessitado. Se, na psicanálise tradicional, o ser humano é movido pelos representantes do desejo, para a psicanálise winnicottiana, o que move o homem é a tendência à integração.

No final da vida (Winnicott, 1986a), diante de uma platéia de padres anglicanos, Winnicott, de acordo com sua particular concepção de saúde, resumiu, de forma simples, quando um indivíduo necessita de ajuda psicológica ou quando o próprio meio ambiente social e familiar pode suprir suas necessidades:

Se uma pessoa vem falar com você e, ao ouvi-la, você sente que ela o está entediando, então ela está doente e precisa de tratamento psiquiátrico. Mas, se ela mantém o seu interesse independente da gravidade do seu conflito ou sofrimento, então você pode ajudá-la. (Winnicott, 1986a, p. 01)

Winnicott só pôde responder aos padres depois de muito pensar, pois estava diante da dificuldade de postular a aparente obviedade: quando alguém está realmente doente e precisa de ajuda especializada? Como destacou Khan

(5) Este termo é usado pelo Prof. Dr. Zeljko Loparic, não apenas em seus trabalhos filosóficos sobre a ontologia de M. Heidegger, como também em sua leitura de Winnicott, feita à luz da filosofia heideggeriana. 
(1986, IN: Winnicott, 1986a, p. 03), Winnicott respondeu à "simples" questão a partir da teoria da comunicação em psicanálise:

O paciente que nos oferece uma narrativa entediante não está permitindo que a linguagem e a metáfora elaborem ou modifiquem a sua experiência. Ele cria um espaço de comunicação onde ambos - ele e o analista-ficam paralisados pela técnica da narrativa, assim como pela monotonia e pela repetição do conteúdo. ${ }^{6}$ (Khan, Masud M. 1986. IN: Winnicott, 1986a, p. 03)

O paciente impede o real contato pessoal, a troca, as comunicações significativas, as experiências de mutualidade, o brincar e a autêntica associação livre. Ele teme repetições de invasões ambientais que o obriguem a reagir. Este é o conceito de trauma adotado por Winnicott - "a quebra de continuidade na existência" (Winnicott, 1967, p. 04) -, que necessariamente varia de acordo com o grau de imaturidade, dependência da criança e de presentificação do senso de desesperança que a impede de ter um real encontro humano.

Como relatado acima, o paciente, ou a criança, tenta ter controle onipotente (contrariamente às experiências de onipotência decorrentes do processo de ilusão, que gradualmente favorecerão a aquisição da externalidade) sobre seu estado emocional, buscando restringir as possibilidades de que algo aconteça. Essa é a raiz de seu sofrimento: não pode ter esperanças, não pode ser surpreendido, não pode acontecer - seu processo de amadurecimento está estagnado. A vida está presa a uma perpétua repetição de seu sofrimento. Contrariamente à saúde, esses indivíduos não desenvolvem um senso de existir, nem podem realizar alguns de seus potenciais, não conseguem brincar. (Winnicott, 1970, p. 282)
As perguntas a serem feitas são: de que maneira o ambiente imediato da criança falhou para que resultasse em uma estagnação de seu processo de amadurecimento? De que forma poderá ser auxiliada pela relação analítica?

As respostas a essas questões só poderão ser compreendidas se, primordialmente, o psicoterapeuta puder brincar com a criança, sustentar essa relação no tempo e espaço da consulta e, principalmente, esperar a comunicação da criança em sofrimento, acreditando nos processos integrativos da própria criança. Esperar significa conduzir clinicamente o processo da consulta ou sessão analítica a partir do ritmo e do manejo da temporalidade própria a cada criança. O tempo na constituição psíquica dos indivíduos é tão importante para Winnicott a ponto de afirmar, em Natureza humana (1988) que o ser humano é uma amostra temporal dessa natureza.

Já em 1941, Winnicott, ao descrever o jogo da espátula (Winnicott, 1941), destacou a importância do manejo da temporalidade nas situações clínicas.

Esse jogo criado com finalidade diagnóstica, e desenvolvido por meio do contato com crianças muito pequenas, surgiu a partir de sua prática pediátrica. O jogo da espátula pode ser tomado como uma ilustração do método terapêutico de Winnicott, da instrumentalização analítica a partir de suas observações e do desenvolvimento de seu pensamento. (Safra, 1999a)

Neste artigo, traduzido sob o título Observação de bebês em uma situação estabelecida (1941), Winnicott conta o desenrolar da situação clínica (e, conseqüentemente, o manejo da temporalidade) caracterizada por três etapas distintas, em que descreve os comportamentos dos bebês (inicialmente no colo de suas mães) diante de uma espátula disponível sobre uma mesa.

\footnotetext{
(6) Cabe destacar que os comportamentos artificialmente saudáveis (a que Winnicott chama de "fuga para a sanidade") ou agradáveis - reações contradepressivas e tentativas de sedução - chegam a provocar irritação no analista (pela falta de autenticidade). A "performance", em determinado momento, torna-se repetitiva e entediante, tendendo a escravizar o analista, que se vê obrigado a assistir a uma falsa tentativa de comunicação; contudo, ele "terá que aprender a tolerar esse discurso forjado, a fim de ajudar o paciente." (Winnicott, 1986a, p. 04). Para Winnicott, não há nada mais entediante que a ausência de dúvidas, fruto da doença e da negação da precariedade da condição humana. (Winnicott, 1969, p. 205)
} 
A partir do momento em que o bebê se sentia atraído pela espátula, uma seqüência de eventos era esperada. Após o despertar do interesse, o bebê passava a hesitar diante da possibilidade de apreender a espátula. Durante esse primeiro período, após observar as reações das pessoas à sua volta, o interesse gradualmente voltava a aparecer, se não interrompido ou apressado pelas pessoas envolvidas.

Em um segundo momento, o interesse aumentava e ocorria uma verdadeira transformação na criança. Sua boca ficava flácida, a língua espessa e a saliva ficava abundante. Em vez de hesitação, surgia autoconfiança e, assim, o bebê agarrava a espátula, que passava a ser manipulada para auto-expressão, ou para iniciar um jogo em que a criança brincava ${ }^{7}$ de alimentar o médico e/ ou a mãe.

Em um terceiro momento, o bebê, como que descuidadamente, deixava cair a espátula no chão. Sendo-lhe restituída, a espátula passava a ser jogada propositalmente, dando grande alegria à criança. Com o passar do tempo, o bebê estabelecia interesse por outros objetos da sala. Nesse momento, Winnicott entendia que a consulta podia ser terminada. Diante dessas consultas com bebês muito jovens, Winnicott compreendeu a experiência vivida pela criança como um processo terapêutico de lição de objeto.

Winnicott considerou essa seqüência de eventos como normal em crianças psiquicamente sadias dentro da faixa dos cinco aos treze meses de idade. Depois disso, em geral, o interesse da criança torna-se tão amplo e variado, que para tal procedimento, nada pode ser predito em relação a inibições, ansiedades ou paradas no seu desenvolvimento.

Em 1941 Winnicott já havia demarcado alguns dos pontos que o guiariam ao longo de todo o seu trabalho analítico: a indissociabilidade entre diagnóstico e tratamento psicanalítico, a importância do brincar na vivência de comu- nicação e mutualidade entre analista e paciente e, principalmente, o veio terapêutico analítico voltado à promoção de experiências constitutivas e lições de objeto (Winnicott, 1941). Em Consultas terapêuticas (Winnicott, 1971b), esses aspectos reaparecem em toda a sua importância. As consultas terapêuticas se fundam sobre as lições de objeto, que nada mais são que o favorecimento pelo psicoterapeuta ao paciente - por meio do campo transferencial - das funções ambientais necessárias à efetivação de aspectos fundamentais do si-mesmo (self) do paciente que até então não haviam tido possibilidade de se constituir. (Safra 1995, 1999a, 1999b, 2000)

O importante é que o encontro possa ser criado pelo paciente no momento da necessidade. Aspectos fundamentais para o estabelecimento na clínica, do que Winnicott denominou espaço potencial, campo inter-humano, fruto do encontro do gesto da necessidade com o objeto necessitado. Uma vez que a comunicação é estabelecida, segundo esses princípios, em algum momento ela precisa ser finalizada. A finalização ocorre no momento em que o objeto criado pela necessidade deixa de ser necessitado [Isso porque o paciente encontrou-o através do encontro analítico, isto é, houve uma lição de objeto]. O paciente 'livra-se' do psicoterapeuta como interlocutor, como objeto necessitado, para colocá-lo fora da área dos seus objetos subjetivos (objeto criado pela necessidade). (Safra, 2000, p. 137)

Apesar de, nesse artigo de 1941, Winnicott afirmar que seu objetivo não era o desenvolvimento de uma terapêutica, ele não deixa de salientar o valor terapêutico da possibilidade de realização de uma experiência completa significativa para a criança e que Safra destaca como a principal finalidade terapêutica das consultas.

A experiência de ousar querer e pegar a espátula, tomar posse dela, sem na verdade

(7) Em seu artigo de 1941, Winnicott procurou destacar o fato de que o bebê se zangava quando suas brincadeiras eram estragadas pelos adultos que haviam compreendido seus comportamentos enquanto tentativas efetivas de alimentação. Já em 1941, Winnicott, diante da rica observação clínica que acumulara no exercício da pediatria, salientou a precocidade com que o brincar surge, assim como o seu caráter primordial relativo ao estabelecimento da saúde psíquica humana. 
alterar a estabilidade do meio ambiente imediato, age como uma espécie de lição de objeto que tem um valor terapêutico para a criança. [...] O que há de terapêutico nesse trabalho está, penso eu, no fato de o desenvolvimento completo de uma experiência ser permitido. (Winnicott, 1941, p. 66-67)

A permissão de um desenvolvimento completo de uma experiência significa, em termos técnicos analíticos, a sujeição dos objetivos terapêuticos ao ritmo dado pelo próprio paciente ao processo, tão bem ilustrado pelo desenvolvimento das consultas terapêuticas, em que assumem uma duração de acordo com cada criança atendida. Favorecendo experiências totais, Winnicott procurava encaminhar seus atendimentos, quer em seu trabalho segundo a demanda, descrito em Piggle: relato do atendimento psicanalítico de uma menina (Winnicott, 1977), quer em suas sessões regulares de psicoterapia (Winnicott, 1986a), quer em suas consultas terapêuticas (Winnicott, 1971b).

Como já se disse, todos os procedimentos clínicos de Winnicott são decorrência direta ou indireta de suas observações das interações mãe-bebê, protótipo da relação analista-paciente na clínica winnicottiana (Dias, 1999, 1998; Loparic, 1996) e na condução do trabalho clínico em consultas terapêuticas.

No manejo intuitivo de um bebê, uma mãe permite, de forma natural, a ocorrência do completo desenvolvimento de várias experiências, mantendo essa atitude até que a criança tenha idade suficiente para compreender seu ponto de vista. Ela detesta violar experiências tais como a amamentação, o sono, ou a evacuação. Nas minhas observações, artificialmente dou ao bebê o direito de completar uma experiência que tem particular valor para ele como uma lição de objeto. (Winnicott, 1941, p. 67)

Sem dúvida alguma, a clínica winnicottiana está respaldada no valor atribuído à experiência. Dessa forma, na clínica de Winnicott, ocorre uma reordenação da prática psicanalítica, em que o corpo, a existência psicossomática, a sensorialidade e as dimensões espaço e tempo são revalorizados e reconsiderados como necessários à constituição de um certo sentido de ser (simesmo), do psiquismo e da situação analítica. (Safra, 1999b)

Por meio da prontidão psicossomática do analista e da identificação com o seu paciente, busca-se favorecer uma relação pessoal especializada em um espaço-tempo da consulta, em que o brincar é franqueado ao paciente, podendo ambos serem surpreendidos com a comunicação (da dificuldade do paciente) que surge inesperadamente do encontro.

Uma vez favorecida a previsibilidade e a confiabilidade ambientais/profissionais para a efetivação do processo de ilusão, de que maneira a emergência do brincar possibilita a comunicação autêntica entre os membros do encontro analítico?

Segundo Winnicott, é somente por meio da terceira área de experiência que a comunicação autêntica se torna possível, graças à peculiaridade da linguagem lúdica que, ao mesmo tempo que revela, oculta. Isso se deve porque, somente por meio do brincar mútuo, a comunicação humana se realiza sem violar o núcleo mais secreto do si-mesmo do paciente. (Winnicott, 1963). Tal como afirma Winnicott: "É uma alegria estar escondido, mas um desastre não ser encontrado". (Winnicott, 1958b)

Sugiro que normalmente há um núcleo da personalidade que corresponde ao simesmo verdadeiro da personalidade split; sugiro que este núcleo nunca se comunica com o mundo dos objetos percebidos, e que a pessoa percebe que não deve nunca se comunicar com, ou ser influenciado pela realidade externa. Este é meu ponto principal,o ponto do pensamento que é o centro de um mundo intelectual e de meu estudo. Embora as pessoas normais se comuniquem e apreciem se comunicar, o outro fato é igualmente verdadeiro, que cada indivíduo éisolado, permanentemente sem se comunicar, permanentemente 
desconhecido, na realidade nunca encontrado.[...] eu diria que as experiências traumáticas que levam à organização das defesas primitivas fazem parte da ameaça ao núcleo isolado, da ameaça dele ser encontrado, alterado, e de se comunicar com ele. A defesa consiste no ocultamento ulterior do si-mesmo [self], mesmo no extremo de suas projeções e de sua disseminação infindável. (Winnicott, 1963, p. 170)

Winnicott define que os instrumentos psicanalíticos, se mal empregados, poderão perpetuar certos graus de violência aos indivíduos. Assim sendo, por intermédio do brincar, até mesmo os procedimentos aceitos nas análises de adultos foram modificados por Winnicott em virtude de sua ênfase no gesto espontâneo do paciente, nas coesões psicossomáticas entre analista e paciente e no que denominou "experiências de mutualidade" na situação analítica, ou "continuidade do ser".

Uma vez que a clínica winnicottiana sustenta-se sobre a acontecência das comunicações e dos encontros humanos, o psicoterapeuta passa a estar em disponibilidade para o paciente como pessoa que ele é, de tal maneira que, por meio do jogo participativo e mútuo dos rabiscos (em consultas terapêuticas), o paciente possa usar dessa relação para manifestar suas necessidades. Nesse sentido, Winnicott afirma:

Eu mesmo trouxe a público essas descrições como um ser humano não exatamente igual a qualquer outro ser humano, de modo que em nenhum caso o mesmo resultado teria sido obtido se em meu lugar estivesse qualquer outro psiquiatra. (Winnicott, 1971b, p. 14)

Assim sendo, cada consulta tem um desfecho próprio, ditado inclusive pelas limitações e capacidades daquele que oferece auxílio. $\mathrm{Na}$ realização das consultas, o psicoterapeuta responsabiliza-se pelas suas ações, e precisa ser capaz de transformar suas falhas em auxílio ao paciente. Com relação à importância dada por Winnicott à pessoa do analista e ao seu próprio processo de amadurecimento, no prefácio de Consultas terapêuticas (1971b), afirma:

É desnecessário dizer que o terapeuta deve ter a confiança profissional como algo que acontece com facilidade; é possível, para uma pessoa séria, manter uma atitude profissional, mesmo quando experimenta tensões pessoais muito fortes na vida privada e no processo de crescimento pessoal que, esperamos, nunca cessa. [...] Uma experiência de intenso tratamento analítico pessoal é, tanto quanto possível, essencial. (Winnicott, 1971b, p. 10)

Não podendo ser diferente, como criador da teoria do amadurecimento humano, Winnicott não submete somente as conduções clínicas ao seu quadro teórico (e vice-versa), mas inclui a própria pessoa do analista.

Em última instância, o psicoterapeuta busca favorecer a comunicação do paciente sobre sua problemática, recolocada sob domínio do eu, graças à presença viva e sensível de um outro ser humano, que funciona como apoio egóico à integridade buscada pelo paciente. Nos casos em que a criança é incapaz de brincar, ou seja, de desfrutar do estabelecimento do espaço potencial, o objetivo da intervenção concentra-se em dar condições para que um dia venha a brincar. Nesses casos, a incapacidade para a brincadeira é o maior sintoma do sofrimento psíquico da criança, havendo uma variação dos objetivos terapêuticos das consultas em virtude da situação psíquica de cada paciente em questão.

\section{AS CONSULTAS TERAPÊUTICAS E A CLÍNICA WINNICOTTIANA}

Por meio de um breve apanhado teórico buscou-se demonstrar não somente uma nova modalidade de intervenção, avaliação e ajuda psicológica criada por Donald W. Winnicott e denominada consultas terapêuticas, mas também apresentar uma ampliação na forma de realizar clínica psicanalítica. 
Neste breve artigo, buscou-se iluminar a consulta terapêutica enquanto uma nova possibilidade de intervenção psicológica realizada sob a condução do manejo do tempo em relação ao pedido de ajuda do paciente.

A consulta terapêutica busca favorecer um tempo, um espaço e uma relação humana especial dos quais possa emergir, pelo contato analítico, a problemática mais significativa do paciente, por um fenômeno marcado pela surpresa (tanto para o paciente quanto para o analista). Tal fenômeno, fruto do processo de comunicação estabelecida entre paciente e terapeuta, aglutina a problemática mais significativa do paciente devido à confiabilidade e previsibilidade fornecidas pelo psicoterapeuta. O elemento-surpresa indica que aspectos anteriormente dissociados da personalidade do paciente foram integrados por meio do encontro.

A partir da valorização dos manejos clínicos (em oposição ao uso exclusivo da interpretação oral como único veículo de intervenção psicanalítica) e das experiências constitutivas do si-mesmo do paciente por meio do brincar compartilhado, demonstrou-se a mútua influência entre a prática clínica de Winnicott e seu modelo conceitual - fundamentado em sua teoria do amadurecimento humano.

\section{REFERÊNCIAS BIBLIOGRÁFICAS}

DIAS, Elsa O. (1998). A teoria das psicoses em Winnicott. Tese (doutoramento), Pontifícia Universidade Católica de São Paulo, São Paulo.

DIAS, Elsa O. (1999). "Sobre a confiabilidade: decorrências para a prática clínica", Natureza Humana, I (02), 283-322.

DSM-IV - Manual diagnóstico e estatístico de transtornos mentais. (1995). 4. ed. Porto Alegre, Artes Médicas.

KHAN, Masud M. (1978). Prefácio. Em: WINNICOTT, D. W. (1978). Textos selecionados: da pediatria à psicanálise. Rio de Janeiro, Francisco Alves.
KHAN, Masud M. (1984). Psicanálise: teoria, técnica e casos clínicos. Rio de Janeiro, Francisco Alves.

KHAN, Masud M. (1986). Prefácio. Em: WINNICOTT, D. W. 1986a. Holding e interpretação. São Paulo, Martins Fontes.

LESCOVAR, Gabriel Z. (2001). Um estudo sobre as consultas terapêuticas de D. W. Winnicott. Dissertação (mestrado). Pontifícia Universidade Católica de São Paulo, São Paulo.

LOPARIC, Zeljko (1996). Winnicott: uma psicanálise não-edipiana, Percurso, no. 17 (02), 41-47.

ORGANIZAÇÃO MUNDIAL DA SAÚDE (1993). Classificação de transtornos mentais e de comportamento da CID-10: descrições clínicas e diretrizes diagnósticas. Porto Alegre, Artes Médicas.

SAFRA, Gilberto. (1995). Momentos mutativos em psicanálise: uma visão winnicottiana. São Paulo, Casa do Psicólogo.

SAFRA, Gilberto. (1999a). A clínica em Winnicott, Natureza Humana, I (01), 91-102.

SAFRA, Gilberto. (1999b). A face estética do self: teoria e clínica. São Paulo, Unimarco.

SAFRA, Gilberto. (2000). Psicoterapia breve: uma reflexão, Psychê: revista de psicanálise, IV (05), 133-139.

STRACHEY, James. (1934). The nature of the therapeutic action of psychoanalysis, International Journal Psycho-Anal., 15.

WINNICOTT, Donald W. (1930). Clinical Notes on Disorders of Childhood. Londres: Heinemann.

WINNICOTT, Donald W. (1941): Observação de bebês em uma situação preestabelecida. Em: WINNICOTT, Donald. W. (1993). Textos selecionados: da pediatria à psicanálise. Rio de Janeiro, Francisco Alves. 4 ed.

WINNICOTT, Donald W. (1945). Desenvolvimento Emocional Primitivo. Em: WINNICOTT, Donald. W. (1993). Textos selecionados: da pediatria à psicanálise. Rio de Janeiro, Francisco Alves. 4 ed. 
WINNICOTT, Donald W. (1954). Aspectos clínicos e metapsicológicos da regressão dentro do setting psicanalítico. Em: WINNICOTT, Donald W. (1993). Textos selecionados: da pediatria à psicanálise. Rio de Janeiro, Francisco Alves. 4 ed.

WINNICOTT, Donald W. (1955): Variedades clínicas da transferência. Em: WINNICOTT, Donald W. (1993). Textos selecionados: da pediatria à psicanálise. Rio de Janeiro, Francisco Alves. 4 ed.

WINNICOTT, Donald W. (1958a). Collect papers: through pediatrics to psychoanalysis. Londres, Hogarth Press and The Institute of Psycho Analysis. (Trad. bras.: WINNICOTT, Donald W. (1993). Textos selecionados: da pediatria à psicanálise. Rio de Janeiro, Francisco Alves. 4 ed.

WINNICOTT, Donald W. (1958b). A capacidade para estar só. Em: WINNICOTT, Donald W. (1983). Ambiente e seus processos de maturação. Porto Alegre, Artes Médicas. 3. ed.

WINNICOTT, Donald W. (1960). Teoria do relacionamento paterno-infantil. Em: WINNICOTT, Donald W. (1983). Ambiente e seus processos de maturação. Porto Alegre, Artes Médicas. 3. ed.

WINNICOTT, Donald. W. (1962a). Os objetivos do tratamento psicanalítico. Em: WINNICOTT, Donald W. (1983). Ambiente e seus processos de maturação. Porto Alegre, Artes Médicas. 3. ed.

WINNICOTT, Donald W. (1962b). A integração do ego no desenvolvimento da criança. Em: WINNICOTT, Donald W. (1983). Ambiente e seus processos de maturação. Porto Alegre, Artes Médicas. 3. ed.

WINNICOTT, Donald W. (1963). Comunicação e falta de comunicação levando ao estudo de certos opostos. Em: WINNICOTT, Donald W. (1983). Ambiente e seus processos de maturação. Porto Alegre, Artes Médicas. 3. ed.

WINNICOTT, Donald W. (1964). A importância do setting no encontro com a regressão em psicanálise. Em: WINNICOTT, Donald W.
(1994). Explorações psicanalíticas. Porto Alegre, Artes Médicas Sul.

WINNICOTT, Donald W. (1964-1968). O jogo de rabisco. Em: WINNICOTT, Donald W. (1994). Explorações psicanalíticas. Porto Alegre, Artes Médicas Sul.

WINNICOTT, Donald W. (1965a). Um caso de psiquiatria infantil que ilustra a reação retardada à perda. Em: WINNICOTT, Donald W. (1994) Explorações psicanalíticas. Porto Alegre, Artes Médicas Sul.

WINNICOTT, Donald W. (1965b). O valor da consulta terapêutica. Em: WINNICOTT, Donald. W. (1994). Explorações psicanalíticas. Porto Alegre, Artes Médicas Sul.

WINNICOTT, Donald W. (1965c). O conceito de trauma em relação ao desenvolvimento do indivíduo dentro da família. Em: WINNICOTT, Donald W. (1994). Explorações psicanalíticas. Porto Alegre, Artes Médicas Sul.

WINNICOTT, Donald W. (1967). O conceito de indivíduo saudável. Em: WINNICOTT, Donald. W. (1999). Tudo começa em casa. São Paulo, Martins Fontes. 3 ed.

WINNICOTT, Donald W. (1969). A pílula e a lua. Em: WINNICOTT, Donald W. (1999). Tudo começa em casa. São Paulo, Martins Fontes. 3 ed.

WINNICOTT, Donald. W. (1970). O lugar da monarquia. Em: WINNICOTT, Donald W. (1999). Tudo começa em casa. São Paulo, Martins Fontes. 3 ed.

WINNICOTT, Donald W. (1971a). Playing and reality. England: Penguin Books. (Trad. bras.: WINNICOTT, Donald W. (1975). O brincare a realidade. Rio de Janeiro, Imago).

WINNICOTT, Donald W. (1971b). Therapeutic consultations in child psychiatry. Londres: Hogarth Press and Inst. of Psychoanalysis. (Trad. bras.: WINNICOTT, Donald. W. (1984). Consultas terapêuticas em psiquiatria infantil. Rio de Janeiro, Imago).

WINNICOTT, Donald W. (1977). The Piggle: an account of the psycho-analytic treatment of a 
little girl. Londres: Hogarth Press. (Trad. bras.: WINNICOTT, Donald W. (1987). The Piggle: relato do tratamento psicanalítico de uma menina. Rio de Janeiro, Imago. 2 ed.).

WINNICOTT, Donald W. (1986a). Holding and Interpretation. Londres: Hogarth Press. (Trad. bras.: WINNICOTT, Donald W. (1991). Holding e Interpretação. São Paulo, Martins Fontes).
WINNICOTT, Donald W. (1988). Human Nature. Londres: Free Association Books. (Trad. bras.: WINNICOTT, Donald W. (1990). Natureza humana. Rio de Janeiro, Imago.

Recebido para publicação 3 de outubro de 2003 e aceito em 14 de abril de 2004. 
